\title{
RELAÇÕES ENTRE MÚLTIPLAS REDES NO BAIRRO ALTO (LISBOA)*
}

\section{Heitor Frúgoli Jr.}

* Versão modificada de trabalho apresentado no 35० Encontro Anual da Anpocs (2011), no GT Dimensões do urbano: tempos e escalas em composição . Agradeço aos comentários do querido professor Gilberto Velho (in memoriam) e dos demais presentes, bem como à leitura atenta de Graça Cordeiro, de participantes do Grupo de Estudos de Antropologia da Cidade (Geac) e dos pareceristas. Este artigo sintetiza tópicos da pesquisa desenvolvida no $1^{\circ}$ semestre de $2011 \mathrm{com}$ bolsa de pesquisa no exterior da Fapesp, mas que também se vale de idas pontuais anteriores (2007, 2008 e 2009), propiciadas pelo CNPq. Agradeço a todos que participaram da pesquisa, ao Centro de Investigação e Estudos de Sociologia do Instituto Universitário de Lisboa (CIES-ISCTE-IUL) pela infra-estrutura oferecida, aos retornos obtidos quando das falas sobre a pesquisa no CIES, na Universidade Lusíada de Lisboa, na Universidade de Coimbra (encontro da Rede Brasil-Portugal de Estudos Urbanos) e na livraria Círculo das Letras, à acolhida calorosa de alguns amigos portugueses ao longo de minha estada e à ajuda de última hora de Marina Frúgoli, Tiago Frúgoli e Márcio Macedo.

Artigo recebido em 23/12/2011

Aprovado em 14/05/2012

\section{Contextualização}

Este artigo apresenta aspectos assinaláveis de uma investigação etnográfica de um bairro específico de Lisboa - o Bairro Alto -, situado na área central e dotado de razoável densidade, lembrando que o próprio conceito de bairro acarreta uma série de desafios para sua apreensão. Um bairro não se apresenta como uma realidade a priori, dado que é marcado por planos e escalas distintos, fronteiras fluidas e alvo de múltiplas representações; também pode abranger uma variação significativa conforme os atores sociais, as instituições e as situações em jogo, bem como os interesses políticos em questão; além disso o conceito leva a diferenciações significativas conforme o recorte disciplinar adotado (Cordeiro e Costa, 1999; Agier, 1999; La Pradelle, 2000; Authier et al., 2006; Vidal, 2009; Frúgoli Jr., 2009).

Priorizou-se aqui a reconstituição de diversas redes de relação que, de certa forma, se condensam num determinado território - no caso o próprio bairro -, ou seja, procurou-se traçar várias conexôes entre agentes, e embora estas possam levar a um panorama mais ampliado e extensivo, também reve- 
lam, como no presente estudo, uma territorialidade mais definida e intensiva (Latour, 1994; Marcus, 1998; Agier, 2011; Frúgoli Jr., 2007; Sklair, 2010).

Ademais, embora sejam inevitáveis classificações e hierarquizações, procuro evitar nessa abordagem a defesa de um ponto de vista "mais legítimo", que poderia ser atribuído, a princípio, aos moradores do bairro em questão, muito embora eles tenham sido levados em conta de forma considerável na pesquisa. ${ }^{1}$ Cabe ainda frisar que em face da tendência recorrente (a começar, pela própria fala de muitos sujeitos) de separar moradores (idosos) e frequentadores noturnos (a chamada "malta jovem") como dois mundos em permanente conflito, procurou-se prestar atenção etnográfica às relações e conexôes (por vezes cotidianas) entre ambos, bem como à configuração de outros tipos de conflito, decorrentes ou não da polaridade básica anterior. ${ }^{2}$

Passemos então uma brevíssima contextualização desse bairro (com passagens mencionadas, retomadas ou reformuladas por vários sujeitos pesquisados). Resumidamente, o Bairro Alto, surgido em $1513,{ }^{3}$ pode ser considerado um bairro popular, histórico e típico de Lisboa (representaçōes essas mais consolidadas a partir do final do século XIX) ${ }^{4}-$ levando-se em conta os múltiplos significados que a ideia de bairro evoca no caso português ${ }^{5}-$, com a predominância (decrescente) de moradores idosos (principalmente senhoras ${ }^{6}$ ), protegidos por leis de congelamento das "rendas" (aluguéis) e que vivem em edifícios envelhecidos, com pouquíssimos investimentos de melhoria por parte de seus proprietários. $^{7}$ Ao longo de sua história, caracterizou-se por certa boemia, mais visível a partir de meados do século XIX, tendo em vista a associação entre fado, prostituição e marginalidade. ${ }^{8}$ Durante o século XIX, o bairro se tornou também um ponto visível da imprensa local, tendo nele sido localizadas as redaçôes dos principais jornais da época. ${ }^{9}$ Nos anos de 1980, o Bairro Alto viveu um período significativo, quando, de modo geral, desdobramentos frustrantes da Revolução dos Cravos $(1974)^{10}$ estimularam mudanças em costumes e atitudes na cidade de Lisboa. Naqueles anos, o bairro serviu como foco central para um novo movimento boêmio, a "movida lisboeta", nome inspirado no movimento espanhol, "la movida madrileña" (pós-franquista), que lhe ser- viu em parte de modelo. ${ }^{11}$ Mais ao final do século $\mathrm{XX}$, o bairro passou a ter um afluxo ainda maior de frequentadores noturnos, incluindo turistas europeus e estudantes ligados ao Programa Erasmus. ${ }^{12}$ À noite, o local se torna um dos pontos mais movimentados da cidade, o que causa vários transtornos aos seus moradores. Chegando ao presente, a cena noturna tem sido assinalada por parcela considerável de frequentadores que consome bebidas alcoólicas nas ruas, ${ }^{13}$ cuja compra (principalmente de cervejas, as "litrosas") é barateada, prática essa identificada como "botellón", outra referência espanhola (por vezes aportuguesada para "botilhão"), em que o consumo coletivo e denso de álcool por grupos juvenis em espaços públicos teria se originado. ${ }^{14}$

De modo geral, o bairro é urbanisticamente delimitado ${ }^{15}$ ao sul, pela Praça de Luís de Camões, Rua do Loreto, Largo do Calhariz e Calçada do Combro, a leste, pela Rua do Século, ao norte, pela Rua Dom Pedro V, e a oeste, pela Rua de São Pedro de Alcântara e Rua da Misericórdia (ver Carita, 1994, e mapa ao final deste artigo); há demarcações "internas", entre o Bairro "mais comercial" ou "mais residencial" (respectivamente "ativo" ou não "ativo", segundo um morador da "parte ativa"), delimitada pela Rua da Rosa, que também separa duas freguesias (Santa Catarina a oeste e Encarnação a leste), cujos domínios raramente coincidem, em Lisboa, com os dos bairros propriamente ditos ${ }^{16} \mathrm{em}$ termos de lazer noturno, novas representações espaciais ganham visibilidade, incluindo a que abrange (por vezes sob a forma de fluxos) uma parte do território da vizinha Bica ("o Bairro Alto está a descer para cá..."). ${ }^{17}$

Cabe ainda nesta introdução mencionar brevemente certas constatações durante a pesquisa que serão retomadas adiante:

Mesmo que algumas representações sobre o Bairro Alto (ou simplesmente Bairro, como muitos o chamam $)^{18}$ sejam acionadas por moradores e comerciantes locais, isso também é feito, evidentemente, por inúmeros frequentadores (atuais e de décadas passadas) que, embora não mais residam ali, tomam tal espaço como parte significativa de períodos de suas vidas ou trajetórias. ${ }^{19}$ 
Diferenças entre representações sobre o Bairro Alto como um espaço boêmio "desde sempre" (expressão portuguesa, recorrente nesse caso) ou principalmente nas últimas décadas, a primeira bastante acionada entre frequentadores da noite ou comerciantes locais, a segunda mais recorrente entre moradores, muito embora outra clivagem possa ser captada, principalmente entre aqueles que fizeram parte da vida boêmia do Bairro entre a década de 1970 e 1980, quando se ressalta as particularidades da vida noturna moderna ali criada, em ruptura com a anterior (popular, marginal, fadista e ligada à prostituição).

Tendo em vista essas ponderaçôes iniciais, passemos à discussão de uma questão recorrente durante as interaçôes etnográficas, relativas à minha condição de antropólogo brasileiro com interlocutores de Portugal, Brasil e Guiné-Bissau, que de certa forma se impôs à pesquisa, seguida da apresentação de duas frentes de investigação relevantes.

\section{Interfaces lusófonas}

Este texto também trata de uma temática advinda do próprio trabalho de campo, decorrente do fato de ser uma pesquisa fora do Brasil, onde também se fala português, mas cuja noção prévia de uma proximidade dada pela língua pode se mostrar por vezes bastante ilusória. Isso leva à necessidade de contrapor tal experiência àquelas realizadas em geral pela antropologia urbana brasileira - na qual me incluo, onde é comum o antropólogo pesquisar a sua própria cidade (Velho, 1978; Durham, 2004 [1986]; Peirano, 1999; Magnani, 2002; Frúgoli Jr., 2011; Eckert e Rocha, 2013).

Uma questão transversal configurou-se ao longo da pesquisa, e embora não constituísse inicialmente um problema, foi posta de forma recorrente pelos sujeitos contatados: o fato de eu ser um pesquisador ${ }^{20}$ brasileiro em Portugal. ${ }^{21}$ Reconheço que não considerei a princípio tal aspecto tão relevante, pelo fato de minha língua nativa ser também o português - o que cria uma perigosa ilusão de proximidade e familiaridade, ou de alteridade próxima ${ }^{22}$
, bem como pela ansiedade em conhecer tal bairro "por dentro". Mas logo se evidenciaram os desafios: em muitas interaçôes, impunham-se variados temas ligados de forma geral à relação entre os dois países: entre as idas de 2007 e 2009, havia menções recorrentes à forte presença de brasileiros em Portugal (algo presente com certas particularidades no Bairro Alto, como retomarei adiante) e por vezes o "recado" era de que o Brasil precisava resolver seus problemas econômicos; em 2011, por sua vez, elogiava-se os avanços da gestão Lula, o que explicaria inclusive certo retorno de imigrantes brasileiros ao Brasil, em contraste com a crise econômica portuguesa (ou europeia, a depender do ponto de vista) - assunto que também se impôs de formas variadas no período mais concentrado de pesquisa. ${ }^{23}$

Eu presumia que, por frequentar certos bares, podia por vezes compartilhar alguns pontos de vista. Um exemplo: durante a Semana Santa, Lisboa recebia um forte afluxo de turistas europeus, e no Bairro Alto se falava bastante na vinda de espanhóis. Num dos feriados, o atendente do balcão de um bar (de frente para o Largo de Camôes ${ }^{24}$ ), num momento bastante atribulado, comentava jocosamente que precisava aprender espanhol e inglês para dar conta de tantos pedidos, e quando comentei que realmente havia muitos estrangeiros por ali naqueles dias, ele respondeu: "Inclusive brasileiros!”. Em outra situação um pouco distinta, após meses de presença regular numa adega do Bairro Alto, fui chamado gentilmente por um dos frequentadores de "meu amigo brazuca", ou seja, se na primeira situação me iludi com o tipo de proximidade que atenuaria minha condição de estrangeiro, ${ }^{25}$ na segunda fui incorporado com a decorrente marcação da diferença.

Outra constatação foi a dificuldade de compreender muitas palavras e expressões (bem como a de me fazer entender), ou mesmo captar o tema central de conversas ou anedotas - principalmente em diálogos cortados, com a participação de várias pessoas -, já que muitas referências regionais (relativas ao Alentejo, ao Minho, ao Algarve etc.) me eram (e algumas continuaram a sê-lo) estranhas. ${ }^{26}$ Como bem lembra Darnton, compreender piadas pode ser uma forma privilegiada de adentrar um sistema cultural (1986, pp. 103-107). 
Certa vez, ao conversar com uma senhora francesa que vive há alguns anos entre Paris e Lisboa (locadora de um apartamento do Bairro Alto), ela falava de dificuldades de interação com os lisboetas, por conta de seus valores e de certa falta de franqueza desses últimos; como eu não os via sob o mesmo prisma, ela então me alertou para não me iludir com a facilidade da língua comum, pois eles seriam fechados, e que talvez fosse bem difícil compreendê-los. ${ }^{27}$ Mesmo que tal argumento partisse de premissas questionáveis, o fato é que, por distintos caminhos, a familiaridade com a língua (portuguesa) ou a não familiaridade com as expressões (dos portugueses) tornavam-se aos poucos desafios equivalentes.

Ainda nessa temática, pode-se também dizer que, principalmente nas estadias de 2009 e 2011, foi possível constatar uma presença significativa de brasileiros no Bairro Alto (principalmente como empregados em bares e restaurantes ${ }^{28}$ ), sem com isso afirmar que tal aspecto seja exclusivo a esse local ou região, embora ali assuma de fato uma densidade significativa. ${ }^{29}$ Isso também me levou a incorporar as especificidades de tais interaçôes na abordagem sobre as redes de relação locais, incluindo o modo recorrente de como brasileiros com quem interagi estabeleciam certa empatia comigo (muitas vezes como "conterrâneos", ainda que com uma maior proximidade pudessem surgir diferenciações, caso por exemplo fossem cariocas, sendo eu paulista). Mesmo isso às vezes levava a novas ilusões de proximidade: alguns brasileiros eram mais impacientes na interação, ou, pelo contrário, achavam que partilhávamos a priori do mesmo ponto de vista; numa noite "brasileira" do Teatro do Bairro, com uma apresentação de "samba de raiz carioca", tomei por brasileiras algumas moças que sambavam com muita elegância, que depois soube serem portuguesas (uma era casada com um dos músicos, outras haviam aprendido com professores brasileiros etc.).

Tais questões de fundo cultural tornaram-se alvo de atenção particular, sobretudo quando passei a interagir, mais tardiamente e por conta dos caminhos da pesquisa (como se verá na última seção deste artigo), com pessoas que vieram da Guiné-Bissau, ${ }^{30}$ quando então era como se desse um outro tipo de aproximação, sem que explicitássemos a respeito: a de não portugueses ou de pós-colonizados que partilham a mesma língua, algo também reforçado por algumas proximidades geracionais, $\mathrm{o}$ que me levou a um outro tipo de experiência no chamado mundo lusófono.

\section{A rua (da Barroca) como foco etnográfico}

Avançando nas interações etnográficas propriamente ditas, que serão aqui parcialmente reconstituídas, pode-se dizer que várias delas se concentraram numa determinada área do Bairro, mais precisamente em certos bares, adegas, tascas e restaurantes ao longo da Rua da Barroca (ver mapa ao final), com atenção também aos tipos de interação ocorridos na própria rua. ${ }^{31}$

Quando ressalto que ali se deu uma vivência mais significativa, isso não quer dizer que outros locais não tenham sido visitados ou percorridos, mas que naquele espaço foi possível estabelecer interações mais duradouras, sem que fosse preciso, com algumas exceções, apresentar-me constantemente ou fazer perguntas (embora praticamente todos soubessem que eu era um pesquisador). Fui também aceito em outros locais do bairro, ainda que isso não configurasse uma territorialidade significativa para interação e observação mais regulares. Em outros casos, houve dificuldades em travar relações iniciais, principalmente em espaços comerciais onde não era possível permanecer por um tempo antes de iniciar uma interação, como, por exemplo, quitandas ou minimercados, expressivamente frequentadas sobretudo pela população local, mas cuja receptividade dos donos, embora não tenha sido hostil, não resultou numa possibilidade de continuidade satisfatória.

Dessa forma, pode-se afirmar que um plano etnográfico privilegiado (em termos de interação e observação) foi a rua (mais precisamente, a Rua da Barroca) e não o bairro, ${ }^{32}$ já que esse não poderia ser diretamente observado, mas recriado através de abordagens variadas - sem a pretensão da reconstituição de uma dada totalidade. É claro que tal escolha acarretou maior visibilidade sobre certos aspectos, mas isso seria inevitável em qualquer microterritório local (com fronteiras também 
extremamente fluidas) que viesse a ser observado mais detidamente, tendo em vista uma abordagem (nessa fase mais prolongada, sem parceiros ou auxiliares) na qual se pretendia certa regularidade de interaçōes. Poder-se-iam mencionar alguns exemplos desses microterritórios, todos eles com dinâmicas que se alteram conforme o período:

- Espaços com fluxos ou concentrações mais turísticas, como a Travessa da Queimada, na qual está o famoso Luso (casa de fado onde Amália Rodrigues iniciou sua carreira), e que conecta o Largo Trindade Coelho (uma das "portas de entrada” do Bairro, onde fica a Igreja de São Roque) ao restaurante Bota Alta (na esquina da Rua da Atalaia) e ao bar Portas Largas (na Rua da Atalaia); ou então a Rua Diário de Notícias, repleta de restaurantes com grande frequência turística, muitos deles com mesas ao ar livre (chamadas, principalmente em Portugal, de "esplanadas").

- Áreas mais ligadas a consumidores (com público predominantemente feminino e juvenil e frequência vespertina) de lojas "modernas" ou "alternativas", como a Rua do Norte.

- Locais com maior densidade (noturna) de brasileiros, como na Travessa da Cara, em torno do Tacão Grande, ou na própria Casa do Brasil (localizada na Rua Luiz Soriano).

- Áreas consideradas mais "perigosas" (parte da Rua do Atalaia ou da Travessa da Cara), por maior incidência de brigas, assaltos ou venda de substâncias ilícitas - embora os dealers (como são chamados os traficantes) estejam acessíveis, nas horas de maior movimento noturno, em várias partes do bairro. ${ }^{33}$

Assim, procurei concentrar a atenção na Rua da Barroca (em períodos diferenciados, até para registrar certas mudanças nos ritmos da apropriação do espaço), ao mesmo tempo em que, como já mencionado, percorri ou visitei outros espaços onde a densidade da observação era inevitavelmente menor.

Desde as primeiras exploraçōes, eu havia concentrado involuntariamente diversos contatos nessa rua, e foi ali que ocorreram interaçóes com maior continuidade, como na Adega da Barroca que, em 2011, passei a frequentar mais regularmente. Vale lembrar que, por vezes, somos também escolhidos por nossos interlocutores, e creio que isso se aplica neste caso. A primeira aproximação com a adega (e também casa de pasto), em 2007, ocorreu a partir de uma conversa com Sr. José, gerente do estabelecimento e morador das proximidades. $\mathrm{O}$ espaço abre ao final da manhã, atendendo frequentadores locais no balcão e se preparando para elaboração das refeições servidas à noite; no fim da tarde, reabre, com o retorno de parte dessa mesma clientela; pouco antes das $20 \mathrm{hs,} \mathrm{o} \mathrm{Sr.} \mathrm{José,} \mathrm{então} \mathrm{com} \mathrm{a} \mathrm{aju-}$ da de sua esposa, passa a atender outros fregueses, que se dirigem para as mesas de refeição, mais ao fundo. Se no período diurno há uma sociabilidade predominantemente masculina, ${ }^{34}$ à noite, o público é mais mesclado, entre mulheres, homens, jovens e turistas. Interessante frisar que tal dinâmica ao longo do dia ajudava a relativizar a muito aludida separação entre os mundos diurno e noturno (mesmo admitindo as delimitaçôes simbólicas existentes).

Neste primeiro contato, já foi possível constatar a participação ativa dos presentes nas conversas (hábito costumeiro em muitos bares, como se sabe), mas diante do aumento de contingente no balcão, o Sr. José não pôde mais conversar. Outro senhor ali presente (Eduardo) centralizou, então, a interação, ${ }^{35}$ discorrendo sobre os bares de alterne ${ }^{36}$ do passado, alguns deles no Bairro Alto, como Lua Nova ou Tia Alice (Arroz Doce), e particularmente sobre um bar noturno cujos frequentadores (na maioria jornalistas) possuíam a chave; também comentou a respeito de jovens brasileiros que trabalhavam (alguns até mesmo residiam) no bairro, e por fim cogitou uma diferença básica entre o Bairro Alto do passado e do presente: "do vinho tinto e branco para a cerveja, vodka, caipirinha, drogas e ladroagem". ${ }^{37}$

Quando estive em Lisboa no ano seguinte (2008), conheci Sr. Celestino Nelson, cujo nome fora citado num jornal local em matéria sobre as marchas populares daquele ano. ${ }^{38}$ Não tive dificuldade de encontrá-lo pelas ruas do Bairro, pois ele frequentava vários estabelecimentos e circulava bastante, transportando gelo, bebidas, frutas, papéis a bares e restaurantes, transmitindo recados etc., ati- 
vidades cuja renda complementava sua "reforma" (aposentadoria). Bastante conhecido no Bairro, ele me apresentou às marchas populares ${ }^{39} \mathrm{em}$ meio a relatos de sua experiência no Rio de Janeiro, como era conhecido o clube comunitário lisboeta responsável pela organização dos desfiles no Bairro Alto. Em nossos breves passeios era evidente seu vasto campo de relaçôes, o que por si só relativizava certa narrativa que tende a apresentar os idosos como mais sedentários e caseiros.

Em nossa última conversa de minha estadia em 2009, ele me disse que gostaria de ganhar a "camisola” (camisa) de algum time brasileiro. Ao retornar a Lisboa, dois anos depois, encontrei-o justamente na Adega da Barroca e pude então presenteá-lo. A receptividade foi significativa não só por parte dele, mas de todos ali presentes, oferecendo-me vinho (prática muito comum entre os portugueses), conversas e mesmo ajuda na pesquisa (como a indicação de outras pessoas para contato), o que se reproduziu ao longo do tempo, tornando ali um dos meus locais de frequência regular, com um rico aprendizado. As interaçôes em tal estabelecimento revelaram-me temas relevantes sobre o cotidiano do bairro, bem como aspectos que extrapolam o plano local e tocam em questões transversais até aqui tratadas.

Por indicação de um dos frequentadores ${ }^{40} \mathrm{ca}$ tólico bastante ativo da Igreja de Santa Catarina, sempre gentil e através do qual pude conhecer um pouco mais a fundo as redes locais ligadas à Igreja Católica, apresentei-me aos donos do bar 89, na Rua da Barroca, que funciona apenas à noite e é gerido por um casal de brasileiros, Mônica e Orlando. Como passei pelo local relativamente cedo, presenciei uma cena muito peculiar: estavam ali conversando, além do casal, os proprietários ou gerentes de outros três restaurantes da rua, Júlia (Baiuca), José (Faia) e Miguel (Taberna da Barroca), o que, como pude constatar, é muito comum acontecer um pouco antes das $20 \mathrm{hs}$, uma vez que os estabelecimentos ainda estão relativamente vazios. Dona Júlia contou-me sua trajetória no Bairro (com relatos sobre a época das tabernas do passado e da prostituição) e como passou de empregada a proprietária do bar Baiuca. Pude entender melhor as interações naquele entorno, com uma teia de sociabilidade que envolve donos e frequentadores de bares e restaurantes, bem como empregados e moradores.

Como já referido, a dimensão da crise econômica e política portuguesa impôs-se de forma muito incisiva em várias situaçôes de pesquisa. Em 23/3/2011, dia da renúncia do então primeiro-ministro português José Sócrates, configurou-se um claro drama em escala nacional. Ao fim da tarde desse dia, na Adega da Barroca, o assunto, trazido por Dona Júlia, fora bastante discutido pelos presentes. No momento do anúncio oficial, realizado pelo próprio Sócrates, estávamos no bar 89 acompanhando a transmissão na TV, enquanto Dona Júlia me contava sobre o ativismo político de seu pai (que a levava a manifestações "como se eu fosse homem") e sua vivência do dia 25 de abril de 1974 , data da Revolução dos Cravos (ela estava grávida, e lembrava-se dos soldados com seus fuzis circulando pela cidade). O contraponto com o que estávamos assistindo naquele momento, que marcava o fim de um ciclo de seis anos de governo do Partido Socialista português e que obviamente gerava um clima de apreensão, motivou uma brasileira ali presente perguntar em tom jocoso se Dona Júlia gostaria de migrar para o Brasil, ao que prontamente ela respondeu com seriedade: "Jamais deixarei Portugal!".

\section{As memórias da década de 1980: novas redes de relação}

A partir dos contatos principalmente efetuados nessa área da Rua da Barroca, passei a reconstituir certas redes de relação com uma territorialidade a princípio mais definida. Contudo, é importante também apresentar, em caráter introdutório, a reconstituição de redes relacionadas com o Bairro Alto, mas cujas conexões me levaram a pessoas ligadas mais especificamente ao passado do Bairro, sobretudo a década de 1980, período simbólico na história da boemia de Lisboa.

$\mathrm{O}$ início dessa reconstituição, na realidade, se deu a partir do contato com Belino Costa, presidente da Associação de Comerciantes do Bairro Alto, colaborador da pesquisa desde 2007. No reencontro com ele em 2011, ganhei um CD-ROM onde estava gravado o vídeo clip Halloween 
(2010). ${ }^{41}$ A ação do filme, com a participação conjunta de transeuntes e atores, se passa justamente na Rua da Barroca, envolta com iluminação especial, fumaça artificial e contendo até mesmo uma intervenção não programada do grupo musical chamado "Homens da Luta" ${ }^{42}$ Dado meu interesse na temática dos usos noturnos contemporâneos locais, entrei em contato com o responsável por sua produção, o lisboeta Xavier Martins, fotógrafo profissional. Conforme ele me relatou, o filme foi realizado com sua câmara digital, cadenciando fotografias em sequência, mas há outros detalhes da interação que cabe assinalar aqui.

Xavier começou a frequentar o Bairro a partir de meados dos anos de 1980, como participante do movimento punk, "onde iniciei minhas aventuras noturnas"; hoje, segundo ele, é o lugar onde sua filha e amigos circulam preferencialmente aos fins de semana. $\mathrm{Na}$ tarde de nosso encontro andamos por ruas e travessas do bairro e ele me apresentou as donas de dois estabelecimentos (uma loja de roupas "vintage" e um estúdio de tatuagens e bodypiercing), o que se desdobrou em contatos muito interessantes. Depois nos encontramos a convite de Belino e do próprio Xavier no lançamento de um CD de Afonso Pais e JP Simóes, Onde mora o mundo, no bar Maria Caxuxa, na Rua da Barroca - bar este que já me chamara atenção em outros anos, por conta da aglomeração de pessoas à sua porta em noites mais movimentadas. Numa rápida conversa com o músico, com treze anos de carreira e quatro CDs lançados, ele contou que considera o Maria Caxuxa uma espécie de "ponto de passagem" para o bar Bica (perto dali), afirmação recorrente durante a pesquisa. Conheci também João Simões, um dos proprietários do Maria Caxuxa, que posteriormente me contou detalhes da criação daquele espaço: uma antiga padaria que fora reformada ${ }^{43} \mathrm{com}$ o intuito de receber um público mais velho do que aquele que predominantemente circula à noite pelas ruas do Bairro e que se relaciona, de um modo geral, ao mundo das artes, da cultura e da música.

A partir do contato com o brasileiro Júlio César, dono dos bares Sétimo Céu (na Travessa da Espera) e do Side (vizinho, na esquina desta travessa com a Rua da Barroca), que me foi apresentado por Xavier, pude reconstruir mais uma territorialida- de circunscrita que, de certa forma, dialoga com a anteriormente descrita, aprofundando meu conhecimento das possíveis conexões ali estabelecidas. A frequentação destes bares configura uma outra rede, formada por gays, transgenders e transexuais que naquela "panasquina" (Henriques, 10/4/2011, p. 5) cria algo bastante nítido em noites de mais fluxo. ${ }^{44}$

Foi-se abrindo, de todo modo, a possibilidade de uma investigação mais baseada em redes de relação e menos territorializada, nas quais o Bairro Alto constitui principalmente um espaço de memória. É que naquela tarde no Maria Caxuxa fui também apresentado a outro fotógrafo, José Luís da Fonseca, nascido no Porto ("tripeiro", como ele próprio afirmou), que acompanhou o surgimento de bares do Bairro Alto no início da década de 1980, quando uma "geração nova, com novas ideias" chegou ao local. Ele fotografou ali "pessoas, festas, sítios, acontecimentos, exposições, poetas a declamar, performances". Lembrou o legendário bar Frágil ${ }^{45} \mathrm{e}$ outros, como Jukebox, Ocarina, Rockhouse ou Os Três Pastorinhos, assinalando que o "ímpeto cultural" daqueles anos levou à criação de discotecas localizadas em outras áreas da cidade, como Plateau, Noites Longas e, mais tarde, o Kremlin. Segundo ele, "todos nos conhecíamos, e íamos escoando", "escorrendo de acordo com gostos", num circuito que se iniciava em bares do Bairro Alto, passava por discotecas e que terminava no Noites Longas, na zona de Santos. ${ }^{46}$ Isso revela um conjunto de espaços e situações vivenciados sobretudo pela geração da década de 1980 , no qual o Bairro Alto teve papel especial.

A sugestão de Luis da Fonseca para que eu entrasse em contato com Hernâni Miguel foi proveitosa, uma vez que ele, juntamente com Zé da Guiné, figura que já fora citada antes por Xavier, Luis e vários outros, deu continuidade à rede e abriu novas dimensões à pesquisa. Hernâni foi o primeiro africano com quem travei relações mais duradouras durante a trabalho de campo. Oriundo de Guiné-Bissau, ainda criança fora adotado por uma família portuguesa durante a guerra colonial. Desde pequeno, ele tinha grande capacidade de fazer contatos, o que é visível em suas inserções na noite lisboeta desde os anos de 1980, desempenhando uma espécie de papel privilegiado de relaçôes públicas. Ele participou, junto com Zé da 
Guiné, do empreendimento que veio a se tornar o já mencionado Noites Longas, ${ }^{47}$ lugar que naquele momento aglutinava toda uma geração que se tornou uma espécie de vanguarda intelectual e artística da cidade, com um poder simbólico que chega a competir com tudo que já foi escrito a respeito do conhecido e afamado bar Frágil. Talvez o fato de este estabelecimento - assim como de Manuel Reis, seu criador - já estar consolidado nas lembranças da época, pode-se perceber certo empenho especial de Hernâni em ressaltar o papel de Zé da Guiné e de si mesmo, na configuração da noite lisboeta moderna, o que, aliás, é referido pontualmente no documentário Crônica de um africano em Lisboa. ${ }^{48}$ Numa cena, a galerista Zambeze Almeida afirma que graças a pessoas como Zé da Guiné, Hernâni Miguel e Manuel Reis, Lisboa teria se transformado em "Lisóptima".

$\mathrm{Na}$ última vez em que estive com Hernâni, ${ }^{49}$ visitamos Zé da Guiné. Fomos recebidos, apesar de todas as dificuldades advindas de sua doença degenerativa, de forma bem humorada - Hernâni, em tom de brincadeira, fez questão de dizer que eu era "um dos nossos". Ele disse estar alegre com a visita recente de alguns amigos, mas triste por certas ausências, e, ainda, fez questão que eu conhecesse um brasileiro que há anos cuidava dele. ${ }^{50}$ Para além da oportunidade de ter conhecido pessoalmente Zé da Guiné, os detalhes sobre construções de pertencimento e formas de aproximação presentes nessa breve conversa fizeram-me pensar sobre os significados inerentes às relações no interior do assim chamado mundo lusófono.

Esta personagem tão contundente teve um passado de luta na guerrilha pela libertação da Guiné-Bissau e, já em Lisboa, trabalhou inicialmente como segurança de alguns bares. Aos poucos foi criando vínculos com a elite intelectual de então e passou a organizar parte da noite lisboeta. ${ }^{51}$ Essa visita ajudou-me a entender melhor sua história, que tinha chegado a mim de forma fragmentada. Articulando o que já vira e ouvira, pude entendê-lo como alguém de rara generosidade, traquejo social, carisma e capacidade performática - ele sabia como ninguém explorar seu corpo atlético, usando roupas exóticas geralmente adquiridas na Feira da Ladra -, o que certamente conferiu àquele contexto um caráter de forte cosmopolitismo. Setores da grande imprensa portuguesa têm tentado evitar seu esquecimento e cobrado do poder público, ou daqueles que vivenciaram com ele aquela época, auxílio para esta pessoa reconhecidamente emblemática que, hoje, contudo, se encontra em situação bastante vulnerável (Belanciano, 2010; Cardoso, 2010).

Ainda que muitos com quem conversei durante a pesquisa fossem os primeiros a se autocriticar a este respeito, tenho plena consciência de que comumente as gerações mais velhas guardam certa nostalgia a respeito de "seu tempo" ou de "sua época", tendendo a ver o presente de forma negativa, o que corrobora a visão atual sobre o Bairro Alto, tendo em vista sua crescente apropriação juvenil, cujo uso disseminado de bebidas alcoólicas ou de substâncias ilícitas ajuda a estigmatizar o local, uniformizando um público bastante heterogêneo e que faz usos diferenciados desses espaços. ${ }^{52}$ De qualquer maneira, a década de 1980 demarca um período relevante na história do Bairro Alto, cabendo avaliar mais detidamente seu potencial de ruptura ou de continuidade com relação ao passado.

A presente pesquisa, cujas abordagens não foram esgotadas nesse artigo, permitiu clarear e introduzir o modo como se dão marcações e interfaces no campo da "lusofonia", um impacto etnográfico não previsto e que, dentre os desdobramentos possíveis, incide sobre a maneira de se pensar questôes relativas aos conceitos de familiaridade e estranhamento no campo da própria antropologia urbana brasileira. Outro prolongamento disso é o foco mais detido nos modos de construção verbal ou nos processos de cognição relativos ao território da cidade, incluindo a negociação de seus mapas e fronteiras simbólicas.

Durante a pesquisa deu-se atenção especial às potencialidades da observação focada nas interações de uma rua específica, marcada pela densidade de relações que envolvem distintos atores sociais, em meio a tudo que a delimita e a compõe - bares, restaurantes, esplanadas, espaços culturais, pequenos comércios e lojas, residências etc. -; espaço que conectado a outros pequenos territórios permitiu um olhar mais preciso, de forma flexível e situacional, sobre o bairro em análise. 
Outra abordagem aqui explorada diz respeito à reconstituição de determinadas redes, procedimento também presente no tipo de investigação aqui empreendido, mas que, neste caso, enveredou o olhar para sujeitos que mantêm com o Bairro Alto uma relação prolongada, ainda que como frequen- tadores da noite, e que, de um lado, recriam o lugar em suas memórias, confrontando-as, de outro lado, com os usos presentes.

Penso assim ter chegado a um conhecimento antropológico mais aprofundado do Bairro Alto de Lisboa, marcado pela sobreposição de experiên-

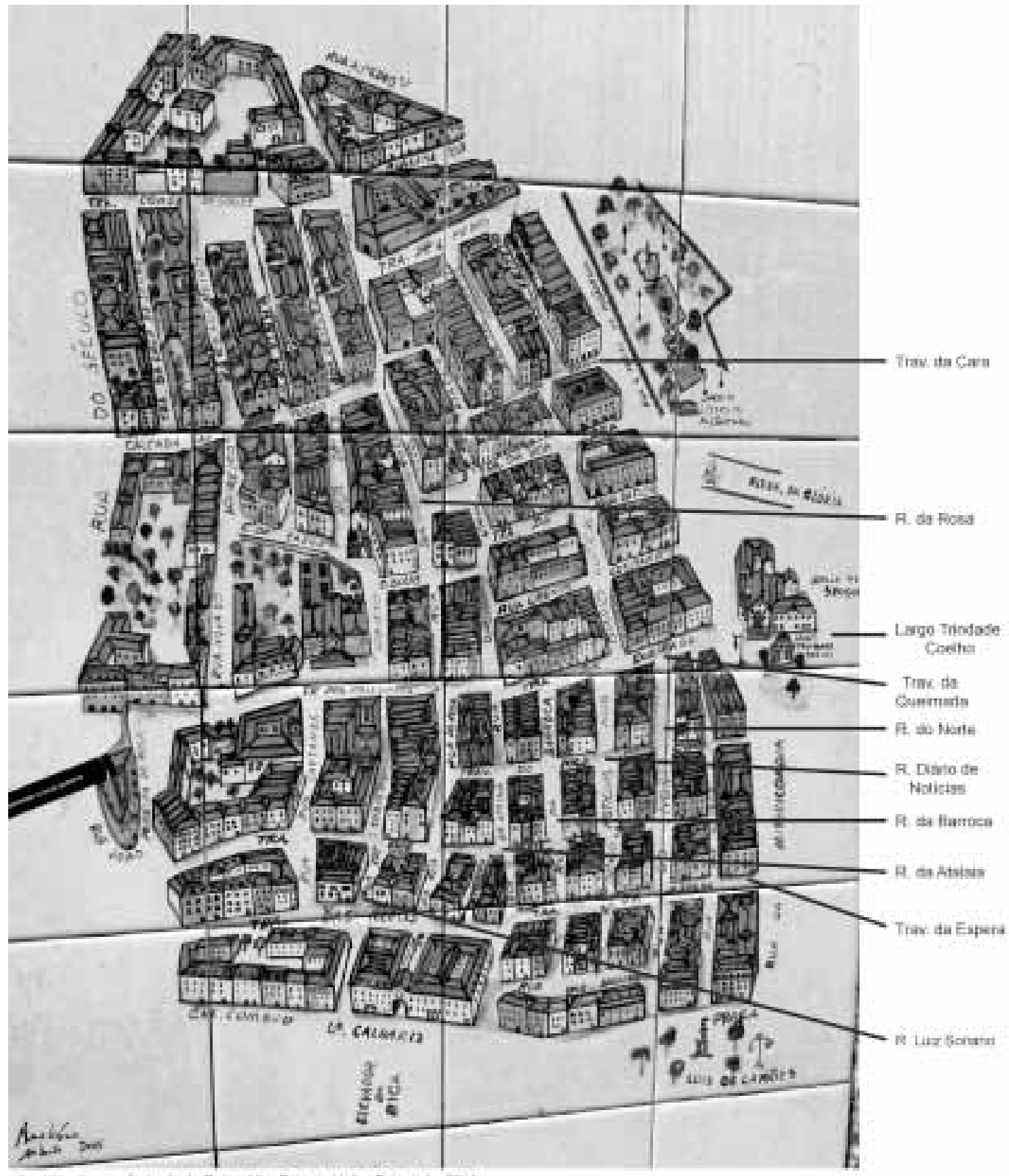


cias de moradia e trabalho com as de boemia, lazer e produção cultural; por enraizamentos combinados a circulações, em meio a vivências geracionais, identitárias e de pertencimentos múltiplos. De um ponto de vista mais amplo, esses aspectos podem auxiliar na compreensão de uma cidade em constante criação de suas dimensões, fronteiras, passados e presentes.

\section{Notas}

1 Para uma abordagem sobre um bairro a partir de práticas espaciais dos moradores, ver Mayol ([1994] 2008). Sobre práticas espaciais de uma forma mais abrangente, ver Certeau ([1980] 1994, pp. 199-215).

2 Ver mais detalhes em Frúgoli Jr. e Sklair (2013).

3 Embora o início do bairro conste em documento assinado em 1498, cujo nome inicial foi Vila Nova de Andrade, depois Bairro Alto de São Roque e finalmente Bairro Alto, com um traçado geométrico que antecipou a reforma urbana pombalina pós-terremoto de 1755 (Carita, 1994, 2006).

4 Ver, a respeito, Cordeiro $(1997,2003)$. Bairro típico é, de um modo geral, uma categoria acionada com recorrência pelos agentes.

5 Para um quadro a respeito, ver Cordeiro (1997), Costa (1999) e Cordeiro e Costa (1999).

6 Ver a respeito o documentário de Marta Pessoa, Lisboa domiciliária (Lisboa, Real Ficção, 2010), que enfoca principalmente idosas, boa parte delas residentes do Bairro Alto.

7 Cf. entrevistas com Filipe Lopes (ex-coordenador do Programa de Reabilitação Urbana de Lisboa, 19902000) e António Miranda (Unidade de Projeto Bairro Alto e Bica UPBAB) (set. 2007).

8 Sobre o vasto tema relativo ao fado e contextos associados, ver Brito (1994, 2004) e Pais ([1985] 2008). Para uma ótima reconstituição literária do Bairro Alto da passagem do século XIX ao XX, ver Sousa (1944); tal atmosfera tinha seu fascínio, tendo despertado a curiosidade em João do Rio (1909), talvez o primeiro brasileiro a escrever sobre o Bairro Alto, quando da sua primeira estadia em Lisboa.

9 Para uma reconstituição histórica, ver Dias (1994, pp. 45-96). Hoje, há apenas um jornal ali instalado, $A$ Bola, cuja impressão é feita em outro local.

10 "Ressaca", como disseram-me alguns. A fala do cineasta português Pedro Costa é muito ilustrativa: Hubo otra cosa importante: aquí vivíamos la post-revolución. Procedíamos de la pequeña y mediana burguesía, de Lisboa o de sus alrededores, y muy rápido, tres años después del 25 de abril, vimos que todo estaba perdido. Entonces nos lanzamos a cosas muy radicales, contra el compromiso político (Neyrat, 2011, p. 17).

11 Nessa época, o surgimento de novos bares e boates no Bairro Alto como, por exemplo, o prestigiado Frágil e a chegada de de artistas plásticos e estilistas trouxeram novos e jovens frequentadores, atraídos especialmente pela vida noturna. A partir de 1986, as Manobras de Maio, desfiles de moda realizados em suas ruas que marcaram época na moda portuguesa, também se tornaram símbolos da nova identidade de Bairro Alto, convertido em espaço de afirmação de valores culturais desse período (cf. entrevista com Belino Costa, lojista e presidente da Associação de Comerciantes do Bairro Alto, set. 2007).

12 Programa de intercâmbio universitário que homenageia Erasmus de Rotterdam, mas que é também um acrônimo inglês de European Region Action Scheme for the Mobility of University Students (ver detalhes em Calvo, 2013).

13 Não apenas no Bairro Alto, embora ali isso se condense e ganhe maior visibilidade pública.

14 Ver matéria recente a respeito em Sobral (2011a).

15 Admitindo-se aqui as fronteiras fluidas de todo e qualquer bairro, muito embora no presente caso haja marcas arquitetônicas que de certa forma demarcam uma morfologia peculiar, que abrange a unidade do traçado urbano, a riqueza de sedimentações arquitectónicas e clareza de limites (Carita, 2006, p. 35), o que não é suficiente, de toda forma, para delimitar suas fronteiras simbólicas.

16 Ver discussão a respeito em Vidal (2009). Acompanhei uma procissão realizada pela Igreja de São Roque (situada no Largo Trindade Coelho, fronteiriço ao bairro; ver o mapa ao final, na parte limítrofe à direita), que tem como itinerário as ruas do Bairro abrangidas pela Junta da Encarnação; a procissão realizada pela Igreja de Santa Catarina (próxima dali, na Calçada do Combro) percorre, quando chega ao Bairro, apenas as ruas ligadas à junta do mesmo nome; em ambas as ocasiōes, chama atenção a presença de idosos (principalmente senhoras) nas janelas (geralmente fechadas no horário noturno).

17 O trabalho de Cordeiro (1997) mostra justamente como as fronteiras da Bica com o Bairro Alto (bem como a própria visibilidade da primeira) são alvos de disputas simbólicas constantes. 
18 Agradeço aos comentários de António Firmino da Costa (quando debati sobre a pesquisa com colegas do ISCTE-IUL em 2009) por apontar o paradoxo de que justamente o Bairro Alto talvez seja o menos bairro entre todos, por abrigar dinâmicas que se relacionariam muito mais com a cidade como um todo do que com um plano local, embora eu entenda que o enfrentamento das relações entre territorialidades e redes possa ajudar a expandir a noção de bairro e ao mesmo tempo preservar um sentido multiplicado de localidade.

19 Contrapontos esses enfrentados por Cordeiro e Costa (1999).

20 Encaravam-me geralmente como um jornalista, embora isso tenha se relativizado ao longo de meus retornos periódicos ao Bairro.

21 Para uma reflexão recente a respeito, ver Feldman-Bianco (2010) e Machado (2010).

22 Nos termos definidos por Peirano (1999), embora aqui eu ressalte justamente o caráter ilusório de tal proximidade.

23 Com reflexos políticos significativos, cuja crise levou à renúncia do primeiro-ministro José Sócrates em março de 2011, como relatarei adiante.

24 Nome coloquial da Praça de Luis de Camões.

25 Para uma reflexão sobre as aproximaçōes entre o estrangeiro, o estranho e o estranhamento, ver Simmel ([1908] 1983). É oportuno mencionar uma passagem do jornalista e escritor José Carlos Oliveira quando em Lisboa em 1975: Então conheci, nesse bar, um homem que ao longo da noite se queixou da vida. Ora, por mais que portugueses e brasileiros se pareçam, em Lisboa sou estrangeiro; quando cá me falam em política, fico em silêncio (2007, p. 417).

26 Ter lido jornal diariamente ajudou-me inclusive a acompanhar parcialmente certas conversas sobre futebol (indispensável para um brasileiro nessas situaçōes), política, economia etc. Uma hipótese para certos mal-entendidos estaria na intenção dos portugueses de ressaltar nossos excessos dedutivos. Num exemplo comum e recorrente, pergunta o brasileiro: O senhor sabe onde fica tal rua? Responde o português: Sei .

27 Mais do que Lévi-Strauss com seus índios, ela arriscou.

28 Há também muitos frequentadores e mesmo casos de donos de estabelecimentos. Machado refere-se, nesse sentido, ao mercado da alegria, propício aos brasileiros devido a qualidades como simpatia e cordialidade (2010, p. 223).

29 É particularmente assinalável a quantidade de bares que oferece música popular brasileira no Bairro Alto, como o Tacão Grande, que pude frequentar por um breve período, antes do término da pesquisa.

30 Principalmente Hernâni Miguel (ver adiante) e seu amigo Rui.

31 Uma parte do Bairro Alto tem a entrada e a saída de veículos controlada, o que restringe bastante tal movimento e incentiva a um uso mais recorrente das ruas como local de circulação e interação.

32 Inspiro-me aqui, dentre outros, em Agier (1999), Cordeiro e Vidal (2008) e Frehse (2009).

33 Agradeço a André Gonçalves, músico morador do Bairro Alto, pelos comentários sobre os dois primeiros territórios, e a Sara Merlini, estudante e frequentadora do Tacão Grande, sobre o terceiro. Quanto ao quarto, reconstituído a partir da observação e de múltiplas vozes, pode-se adicionar que a venda de substâncias ilícitas é diferente (até onde sei) dos contextos brasileiros, já que é comum que os próprios dealers abordem os transeuntes.

34 Para uma abordagem sobre formas de sociabilidade em botequins brasileiros, ver o trabalho pioneiro de Silva ([1969] 1978); sobre demarcaçôes de esferas masculinas e femininas em espaços comerciais de um bairro popular carioca, ver Santos et. al. (1985, pp. 41-46); sobre significados de masculinidade a partir da etnografia de um café em Pardais (Alentejo), ver Vale de Almeida (2000).

35 Que me contou ter servido o exército português em Moçambique, durante a guerra colonial (1961-1974), como várias outras pessoas dessa geração que conheci durante a pesquisa. Em certos momentos finalizava-se o assunto e ele mesmo pedia: outra (pergunta)! .

36 Bares onde mulheres vendem sua companhia a homens, a princípio sem contato sexual posterior, embora haja fronteiras ambíguas com a prostituição.

$37 \mathrm{O}$ vinho tem uma forte simbologia ligada à tradição camponesa em Portugal; em tabernas rurais representa um fator de coesão dotado de forte ritualidade (Brito, 1991, p. 195). Nas palavras de Vale de Almeida, a cultura do vinho carrega, para os locais, o simbolismo da ruralidade e da taberna. A cerveja, como produto engarrafado e comercializado pela publicidade, apela aos valores da sociedade de consumo e renega a produção para o consumo próprio que o vinho simbolizava (2000, p. 183).

38 Ver Padrão (2008, p. 24). Celestino era então porta-estandarte do Lisboa Clube Rio de Janeiro.

39 Cujo desfile na Avenida da Liberdade também assisti 
naquele ano, bem como acompanhei, de forma bem mais detida, em 2011 (ver, a respeito, Frúgoli Jr., 2012).

40 Que também se chama José.

41 Disponível no youtube: <http://www.youtube.com/ watch?v=SElbMnnDYpo $>$, acessado em 20/8/2011.

42 Grupo musical que articula humor com protesto político, e que faz muitas intervenções nos espaços públicos da cidade (ver, a respeito, Vaza, 8/3/2011).

43 Durante a reforma, descobriram-se ali pisos, paredes e colunas da época anterior ao terremoto de Lisboa, o que foi incorporado na ambientação do bar.

44 Embora o Sétimo Céu seja um bar assumidamente gay, existe uma tendência de tal territorialidade se espraiar por vários locais do Bairro e do entorno, como em bares gay-friendly. Por outro lado, Ana Henriques, em matéria de publicada no periódico Público, afirma que espaços antes mais fechados se tornaram aos poucos hetero-friendly. Ademais, se um fluxo significativo de pessoas na alta madrugada vai do Bairro Alto para a região da Bica ou Cais do Sodré, há outro que segue em direção ao Príncipe Real, lugar referencial de concentração desse tipo de público.

45 Eis a descrição por email da escritora Isabel Fraustino, em 2006: Nos anos de 1980 surgiu o Frágil. Foi o primeiro bar moderno do Bairro Alto e de Lisboa, aberto por Manuel Reis (uma figura incontornável da nova noite lisboeta). O Frágil marcou a mudança na cidade, com ele os jovens e os intelectuais começaram a sair à noite para frequentar o Bairro Alto sem serem amantes de fado [...]. Essa movida lisboeta nunca mais parou. Hoje nem sei dizer-lhe quantos bares há; em cada rua encontramos vários e em todos eles há mais gente na rua do que dentro do bar .

46 Como sintetiza o cronista Vítor Belanciano: A meio dos anos de 1980, depois do Bairro Alto adormecer, era para ali [Noites Longas] que a Lisboa artística descia de braço dado e se misturava com a Lisboa castiça do Cais do Sodré e do Mercado da Ribeira (25/8/2010).

47 Ver detalhes de sua trajetória e das parcerias com Zé da Guiné em Sacramento (2004, pp. 46-47).

48 Documentário dirigido por José Manuel de S. Lopes (2011) sobre Zé da Guiné (http://www.zedaguinethemovie.com/welcome.html), que tive a oportunidade de assistir um pouco antes do fim de minha estada em Lisboa, e cujo diretor também contatei.

49 Em certas ocasiōes acompanhei-o em sua circulação pelos bares do Bairro Alto, com visitas rápidas ou permanências mais detidas.
50 Quem infelizmente não pude estabelecer contato por estar, então, a poucos dias do término da pesquisa.

51 Ver, a respeito, Carrilho (2011), além do documentário já citado.

52 Isso foi alvo de falas recorrentes ao longo de todo esse período de pesquisa, tendo inclusive levado a uma primeira tentativa de controle por parte do poder público quando do anúncio de uma futura proposição de restrição do horário de funcionamento das lojas de conveniência, consideradas as principais responsáveis por tal consumo nas ruas (Sobral, 2011b).

\section{BIBLIOGRAFIA}

AGIER, Michel. (1999), Linvention de la ville: banlieues, townships, invasions et favelas. Paris, Archives Contemporaines.

. (2011), "Os saberes urbanos da antropologia” [1997], in . Antropologia da cidade: lugares, situações, movimentos. Tradução de Graça Índias Cordeiro, São Paulo, Terceiro Nome.

AUTHIER, Jean-Yves; BACQUÉ, Marie-Hélène \& GUÉRIN-PACE, France. (eds.) (2006), Le quartier: enjeux scientifiques, action politiques et pratiques sociales. Paris, La Découverte.

BELANCIANO, Vitor. (2010), “Zé da Guiné”. Público, Lisboa, 3 (caderno P2), 25 ago.

BRITO, Joaquim Pais de. (1991), "A taberna: lugar e revelador da aldeia”, in B. J. O'Neill e J. P. de Brito (orgs.), Lugares de Aqui, Lisboa, Dom Quixote.

(COORD.). (1994), Fado: vozes e sombras. Lisboa, Museu Nacional de Etnologia/Electa.

(2004), "As escritas e as ressonâncias da alteridade", in J. M. Pais, J. P. de Brito e M. V. de Carvalho (orgs.), Sonoridades Luso-Afro-Brasileiras, Lisboa, ICS.

CABRITA, António R.; AGUIAR, José \& APPLETON, João (orgs.). (1992), Manual de apoio à reabilitação dos edifícios do Bairro Alto. Lisboa, Câmara Municipal de Lisboa/Laboratório Nacional de Engenharia Civil.

CALVO, Daniel M. (2013), "Procesos de revalorización patrimonial en el barrio de Alfama: 
el papel de los estudiantes Erasmus en la tematización de la ciudad”. Etnográfica, 17 (1): 31-50.

CARDOSO, Miguel E. (2010), "Viva o Zé da Guiné”. Público, Lisboa, s. p., 26 ago.

CARITA, Helder. (1994), Bairro Alto: tipologias e modos arquitetônicos. Lisboa, Câmara Municipal de Lisboa.

. (2006), "A Igreja, a Rua Larga e o

Bairro Alto de São Roque", in M. H. Oliveira (org.), Património Arquitectónico: Santa Casa da Misericórdia de Lisboa, Lisboa, Santa Casa da Misericórdia de Lisboa/Museu São Roque.

CARRILHO, Raquel. (2011), "O homem que fazia acontecer". Sol, 10-12, 9 jun.

CERTEAU, Michel de. ([1980] 1994), A invenção do cotidiano. Vol. 1: Artes de fazer. Tradução de Ephraim F. Alves. Petrópolis, Vozes.

CORDEIRO, Graça I. (1997), Um lugar na cidade: quotidiano, memória e representação no bairro da Bica. Lisboa, Dom Quixote.

(2003), "Uma certa ideia de cidade: popular, bairrista, pitoresca”. Sociologia, XIII: 185-199.

CORDEIRO, Graça I. \& COSTA, António F. da. (1999), "Bairros; contexto e intersecção", in G. Velho (org.), Antropologia urbana: cultura e sociedade no Brasil e em Portugal, Rio de Janeiro, Jorge Zahar.

CORDEIRO, Graça I. \& VIDAL, Frédéric (orgs.), (2008), A rua: espaço, tempo, sociabilidade. Lisboa, Livros Horizonte.

COSTA, António F. da. (1999), Sociedade de bairro: dinâmicas sociais da identidade cultural. Oeiras, Celta.

DARNTON, Robert. (1986), O grande massacre de gatos, e outros episódios da história cultural francesa. Tradução de Sonia Coutinho. Rio de Janeiro, Graal.

DIAS, Marina T. (1994), Lisboa desaparecida. 3 ed. Coimbra, Quimera, vol. 4.

DURHAM, Eunice R. (1986), "A pesquisa antropológica com populações urbanas", in . (2004), A dinâmica da cultura, São Paulo, Cosac \& Naify.

ECKERT, Cornelia \& ROCHA, Ana Luiza C. (2013), Antropologia da e na cidade: interpreta- çôes sobre as formas da vida urbana. Porto Alegre, Marcavisual.

FELDMAN-BIANCO, Bela. (2010), "Brasileiros em Lisboa, portugueses em São Paulo: construçôes do 'mesmo' e do 'outro'”, in B. Feldman-Bianco (org.), Naçôes e diásporas: estudos comparativos entre Brasil e Portugal. Campinas, Editora da Unicamp.

FREHSE, Fraya. (2009), "Usos da rua”, in C. Fortuna e R. P. Leite (orgs.), Plural de cidade: novos léxicos urbanos, Coimbra, Almedina.

FRÚGOLI JR., Heitor. (2007), Sociabilidade urbana. Rio de Janeiro, Jorge Zahar.

(2009), "A cidade no diálogo entre disciplinas", in C. Fortuna e R. P. Leite (orgs.), Plural de cidade: léxicos e culturas urbanas, Coimbra, Almedina.

(2011), "Esboços de uma trajetória: cidade, pesquisa, universidade". Iluminuras, 12 (28): 18-40. Disponível em <http://seer.ufrgs. br/iluminuras/article/view/24878>.

(2012). "Festas populares em Lisboa: uma etnografia a partir do Bairro Alto". Trabalho apresentado na 28a Reunião Brasileira de Antropologia, São Paulo.

FRÚGOLI JR., Heitor \& SKLAIR, Jessica. (2013), "O bairro da Luz (São Paulo) e o Bairro Alto (Lisboa) nos entremeios de mudanças e permanências" in C. Fortuna e R. P. Leite (orgs.), Diálogos urbanos: territórios, culturas, patrimónios. Coimbra, Almedina.

HENRIQUES, Ana. (2011), "A noite gay está a ficar hetero-friendly”. Público, Lisboa, 4-7, 10 abr.

LA PRADELLE, Michèle de. (2000), "La ville des anthropologues", in T. Paquot, M. Lussault e S. Body-Gendrot (eds.), La ville et l'urbain: l'état des savoirs, Paris, La Découverte.

LATOUR, Bruno. (1994), Jamais fomos modernos. Tradução de Carlos I. da Costa. São Paulo, Editora 34.

MACHADO, Igor José de R. (2010), "Imigração brasileira no Porto, Portugal: apontamentos para uma etnografia do jogo da centralidade e dos circuitos de reciprocidade", in B. Feldman-Bianco (org.), Nações e diásporas: estudos comparativos entre Brasil e Portugal, Campinas, SP, Editora da Unicamp. 
MAGNANI, José Guilherme C. (2002), "De perto e de dentro: notas para uma etnografia urbana”. Revista Brasileira de Ciências Sociais, 17 (49): 11-29.

MARCUS, George E. (1998), "Ethnography in/ of the world system: the emergence of multi-sited ethnography" [1995], in G. E. Marcus, Ethnography through thick and thin, Princeton, Princeton University Press.

MAYOL, Pierre. ([1994] 2008), "Morar", in M. Certeau, L. Giard e P. Mayol, $A$ invenção do cotidiano. Vol. 2: Morar, cozinhar. 7 ed. Tradução de Ephraim F. Alves e Lúcia E. Orth. Petrópolis, Vozes.

NEYRAT, Cyril. (2011), "Conversación con Pedro Costa”, in (org.), Un mirlo dorado, un ramo de flores y una cuchara de plata. 2 ed. Barcelona, Intermedio.

OLIVEIRA, José C. (2005), Flanando em Paris. Rio de Janeiro, Civilização Brasileira.

PADRÃO, Isaltina. (2008), "Bastidores das marchas estão cheios de talentos". Diário de Noticias, Lisboa, 24-25, 11 jun.

PAIS, José M. ([1985] 2008), A prostituição e a Lisboa boémia: do século XIX a inícios do século XX. Porto, Âmbar.

PEIRANO, Mariza. (1999), "Antropologia no Brasil (alteridade contextualizada)", in S. Miceli (org.), O que ler na ciência social brasileira (1970-1995), São Paulo/Brasília, Sumaré/Anpocs, vol. 1.

RIO, João do. (1909), Fados, canções e dansas de Portugal. Rio de Janeiro, Livraria Garnier.

SACRAMENTO, Catarina. (2004), "Hernâni Miguel”. Blitz, Lisboa, 46-47, 22 jun.

SANTOS, Carlos N. F.; VOGEL, Arno \& MELLO, Marco A. S. (1985), Quando a rua vira casa: a apropriação de espaços de uso coletivo em um centro de bairro. 3 ed. Rio de Janeiro, Finep/Ibam, 1985.

SILVA, Luiz Antonio M. da. (1978), "O significado do botequim" [1969], in L. Kowarick (org.), Cidades: usos e abusos, São Paulo, Brasiliense.

SIMMEL, Georg. (1983), "O estrangeiro" [1908], in E. Moraes (org.), Sociologia: Simmel. São Paulo, Ática.
SKLAIR, Jessica. (2010), A filantropia paulistana: ações sociais em uma cidade segregada. São Paulo, Humanitas.

SOBRAL, Cláudia. (2011a), "Viagem por uma noite de botellón em Lisboa (Jovens portugueses importam hábitos de consumo espanhóis)". Público, Lisboa, 8-9, 3 abr.

(2011), "António Costa propõe horários reduzidos nas lojas de conveniência do Bairro Alto (Presidente da Câmara quer restringir consumo de álcool na rua à noite)". Público, Lisboa, 24, 12 jun.

SOUSA, Avelino de. (1944), Bairro Alto. Lisboa, Livraria Popular de Francisco Franco.

VALE DE ALMEIDA, Miguel. (2000), Senhores de si: uma interpretação antropológica da masculinidade. 2 ed. Lisboa, Fim de Século.

VAZA, Marco. (2011), "Homens da Luta: não são música de intervenção, mas são intervenção". Público, Lisboa, 8 (caderno P2), 8 mar.

VELHO, Gilberto. (1978), "Observando o familiar”, in E. Nunes (org.), A aventura sociológica. Rio de Janeiro, Jorge Zahar.

VIDAL, Frédéric. (2009), "A mobilidade residencial como objeto da história urbana: registos, práticas e interpretaçôes", in R. M. do Carmo e J. A. Simões (orgs.), A produção das mobilidades: redes, espacialidades e trajectos, Lisboa, ICS. 


\section{RELAÇÔES ENTRE MÚLTIPLAS REDES NO BAIRRO ALTO (LISBOA)}

\section{Heitor Frúgoli Jr.}

Palavras-chave: Bairro; Rua; Redes de relação; Etnografia urbana; Vida noturna.

Formado no século XVI e situado na área central de Lisboa, o Bairro Alto pode ser visto como um bairro popular e típico, com certo predomínio de residentes idosos e que, do ponto de vista histórico, se caracterizou por várias formas de boemia. Nos anos de 1980, deu visibilidade a um novo movimento boêmio, seguido de mudanças que têm atraído um número elevado e crescente de frequentadores, condensando múltiplas redes. Pretende-se neste artigo apresentar alguns resultados de uma etnografia iniciada em 2007, com ênfase em três dimensões: decorrências metodológicas das interações do antropólogo com portugueses, brasileiros e africanos; ênfase das observações sobre uma determinada rua e suas dinâmicas de sociabilidade; reconstituição de determinadas redes de relação que articulam sobretudo frequentadores noturnos do Bairro Alto.

\section{RELATIONS BETWEEN MULTIPLE NETWORKS IN THE BAIRRO ALTO (LISBON)}

Heitor Frúgoli Jr.

Keywords: Neighborhood; Street; Network relationships; Urban ethnography; Nightlife.

Having sprung up in the 16th century, Bairro Alto is a neighborhood located in Lisbon's downtown area and can be considered a typical popular neighborhood, with a predominantly elderly population, which is historically characterized by various forms of bohemian life. In the 1980's, the rise of increased nightlife activities,followed by some changes that occurred in the neighborhood, attracted a growing number of goers from several social networks. The article presents some outcomes from an ethnographical research initiated in 2007, with emphasis on three dimensions: the methodological consequences of the anthropologist's interactions with Portuguese, Brazilian and African persons who frequent the area; the emphasis on observations of a specific street and its sociability dynamics; the reconstitution of some specific networks articulating Bairro Alto night goers.

\section{RAPPORTS ENTRE LES MULTIPLES RÉSEAUX DANS LE BAIRRO ALTO (LISBONNE)}

\section{Heitor Frúgoli Jr.}

Mots-clés: Quartier; Rue; Réseaux; Ethnographie urbaine; Vie nocturne.

Construit au XVIème siècle et situé dans la zone centrale de Lisbonne, le Bairro Alto peut être considéré un quartier populaire et typique, avec une certaine prédominance de résidents âgés. D’un point de vue historique, il s'est caractérisé par diverses formes de vie bohème. Dans les années 1980 un nouveau mouvement bohémien a vu le jour. Les changements qui s'en sont suivis ont attiré un nombre élevé et croissant de personnes, dont la fréquentation a impliqué la formation de multiples réseaux. Cet article a pour but de présenter quelques résultats d'une ethnographie qui a débuté en 2007 en attirant l'attention sur trois dimensions : les conséquences méthodologiques des interactions de l'anthropologue avec les portugais, les brésiliens et les africains ; l'accent sur les observations à propos d'une rue choisie et ses dynamiques de sociabilité ; la reconstitution de certains réseaux qui articulent principalement les personnes qui fréquentent le Bairro Alto la nuit. 